\title{
Preliminary survey of leading general medicine journals' use of Facebook and Twitter ${ }^{1}$
}

\author{
Maged N. Kamel Boulos and Patricia F. Anderson
}

\begin{abstract}
Aim: This study is the first to chart the use of Facebook and Twitter by peer-reviewed medical journals. Methods: We selected the top 25 general medicine journals on the Thomson Reuters Journal Citation Report (JCR) list. We surveyed their Facebook and Twitter presences and scanned their Web sites for any Facebook and (or) Twitter features as of November 2011. Results/Discussion: 20 of 25 journals had some sort of Facebook presence, with 11 also having a Twitter presence. Total 'Likes' across all of the Facebook pages for journals with a Facebook presence were 321,997, of which 259, 902 came from the New England Journal of Medicine (NEJM) alone. The total numbers of Twitter 'Followers' were smaller by comparison when compiled across all surveyed journals. 'Likes' and 'Followers' are not the equivalents of total accesses but provide some proxy measure for impact and popularity. Those journals in our sample making best use of the open sharing nature of social media are closed-access; with the leading open access journals on the list lagging behind by comparison. We offer a partial interpretation for this and discuss other findings of our survey, provide some recommendations to journals wanting to use social media, and finally present some future research directions. Conclusions: Journals should not underestimate the potential of social media as a powerful means of reaching out to their readership.
\end{abstract}

\section{Background and aim}

An increasing number of biomedical journals (and publishers) are establishing social media presences, particularly on Facebook [1, 2] and Twitter [3], but also on other social media spaces such as YouTube and LinkedIn. ${ }^{2}$ Facebook, Twitter, and other social media channels have also been proposed as supportive communication tools for healthcare organizations [4, 5], hospitals [6], and physician leaders [7], and their increased popularity is raising new questions about social-media-powered peer review [8].

Not surprisingly, citations to articles mentioning these tools are steadily increasing in PubMed (Fig. 1).

Facebook, created in February 2003, is one of the most active social networks in the world, with more than 800 million active users worldwide, according to Facebook's own metrics as of November 2011 [9], confirmed by ComScore [10], and has over 150 million unique visitors per month according to site analytics from Compete (November 2011/US Data Only) [11]. More than 50\% of active users $\log$ on to Facebook daily [8]. ComScore has noted that Facebook has experienced a 33\% growth over the past year (2010/2011), and continues to be the dominant social networking tool in the world, with Twitter up $56 \%$ and now in second place $[10,12]$. By any measure, both tools' continued growth rate is impressive.

Facebook has the potential of acting as a 'hub' for different types of media and channels and is starting to change the established patterns of user information seeking behaviour on the Internet and shake up the role of conventional search engines [13]. Users are increasingly discovering new information through Facebook and other social media in place of searching using 'old-fashioned' classic search engines such as Google Search. Google searches no longer accurately represent users' online information finding behaviour [13]. SEO (Search Engine Optimization) and conventional search ranking/visibility of a journal's homepage on Google Search, Bing and Yahoo! search engines are becoming relatively less important as social media dominate the scene, the balance of

M.N. Kamel Boulos.* Associate Professor of Health Informatics, University of Plymouth, Devon, UK.

P.F. Anderson. Emerging Technologies Librarian, University of Michigan, Ann Arbor, MI, USA.

*Corresponding author (e-mail: mnkamelboulos@plymouth.ac.uk).

${ }^{1}$ This article has been peer reviewed.

${ }^{2}$ PLoS (Public Library of Science): http://www.linkedin.com/groups?gid=3484244 (Publisher group example) | New England Journal of Medicine (NEJM): http://www.linkedin.com/company/new-england-journal-of-medicine/(Publisher company example) | Youtube: NEJMvideo (channel): http://www.youtube.com/user/NEJMvideo | Youtube: The JAMA Report (channel): http://www.youtube. com/user/TheJAMAReport 
Fig. 1. Citations to articles mentioning Facebook and Twitter are steadily increasing in PubMed, 2007-2011 (PubMed search strategy used: (Internet OR WWW OR "World Wide Web" OR online OR cyber OR Computer Communication Networks [mh] OR telemedicine) AND (Facebook OR Twitter OR tweet) year [DP]).

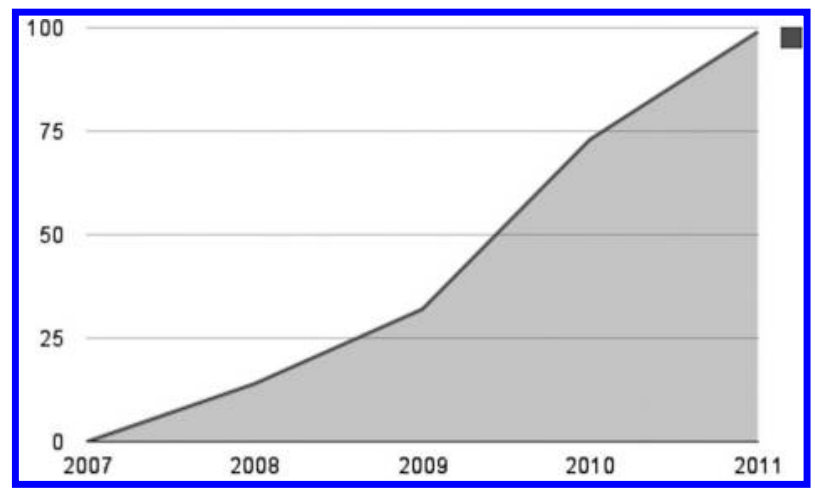

which is hotly debated among experts in both areas $[14,15]$.

Facebook and Twitter are also very well optimised for smartphones and tablets and supported by many apps (applications) running on these devices, which are rapidly becoming the main form of access to the Internet for millions of users worldwide. Today, hundreds of millions of users are doing many online tasks on Facebook, including reading, commenting on, and sharing news articles, an activity that holds great potential for journal publishers looking to expand their reach and impact. 'Google Trends for Websites' shows Facebook gradually widening its existing lead over social media such as YouTube, Twitter, and Wikipedia. ${ }^{3}$

It is therefore not surprising that Nielsen recently reported that Americans now spend more time on Facebook (53.5 billion minutes a month) than on Yahoo! (17.2 billion), Google (12.5 billion), YouTube (9.1 billion), Blogger (724 million), Tumblr (624 million), and Twitter (565 million) combined, a trend that started in 2010 and continued in 2011 (September) [16, 17]. Contrary to the commonly held belief that Facebook is mainly used by teenagers and young adults, a recent Pew survey reported (August 2011) that use of Facebook and other social networking sites is on the rise among those aged 50-64 (51\% of Internet users in this age group use social networking sites), with $33 \%$ of Internet users in the $65+$ age group also using such sites [18, 19]. Furthermore, an American Medical Association (AMA) survey found that nearly all US doctors are now on social media, particularly Facebook and Twitter [20].

To the best of the authors' knowledge, the study presented in this paper is the first of its kind to attempt to document the use of Facebook and Twitter by peerreviewed medical journals. The study is particularly relevant to health science librarians for the following reasons:

- Journals and individual article impact and quality metrics have often been of interest to librarians. With the advent of Facebook and Twitter, new metrics are emerging (e.g., the 'twimpact factor' [21]) and existing metrics are being heavily influenced by the dissemination and discussion of journal articles via Twitter and other social media channels. Librarians, who are often asked to advise on the best places to submit an article for publication, should be aware of these potential contributors to a journal's impact. Librarians are also commonly interested in curating (identifying, filtering/classifying and signposting) new and relevant publications as a service to their audiences. They traditionally subscribe to journals' RSS (Really Simple Syndication) feeds and TOCs (Tables of Contents) for this purpose. Social media (including journal presences on these media) are now becoming important venues for finding and signposting information about new articles and article collections. Being able to advise their clients and institutions on these matters is becoming a core competency. Marton [22] suggests that librarians can assume a leadership role in this respect.

- In academic health librarianship, librarians do more than select and maintain journals for their collections. Medical schools typically have faculty who serve as journal editors and who submit articles. The potential role of librarians as educators and advisors of social media best practices within medical schools and hospitals has been persuasively argued and competently illustrated in the literature [23-25]. The recommendations we are providing at the end of this paper could well be used to improve and promote existing social media pages maintained by librarians and to create new pages to collate and signpost the best posts from select ranges of journals' social media presences, e.g., a general medicine journal collection, as a social media aggregation and curation service.

\section{Methods}

The list of top 25 general medicine journal titles included in the study was selected from the ISI (Thomson Reuters) Journals Citation Reports (JCR) impact factor list (2010 JCR Science Edition, subject category: 'MEDICINE, GENERAL \& INTERNAL'; the selected journals are: NEW ENGL J MED, LANCET, JAMA-J AM MED ASSOC, ANN INTERN MED, PLOS MED, BRIT MED J, ANNU REV MED, ARCH INTERN MED, CAN MED ASSOC J, COCHRANE DB SYST REV, J INTERN MED, BMC MED, MAYO CLIN PROC, AM J MED, ANN FAM MED, ANN MED, MEDICINE,

\footnotetext{
${ }^{3}$ Facebook vs. YouTube: http://trends.google.com/websites?q=Facebook.com $\% 2 \mathrm{C}+$ Youtube.com\&geo $=$ all\&date $=$ all\&sort $=0 \mid$ Facebook vs. Twitter: http://trends.google.com/websites?q $=$ Facebook.com $\% 2 \mathrm{C}+$ Twitter.com $\&$ geo $=$ all\&date $=$ all\&sort $=0 \mid$ Facebook vs. Wikipedia: http://trends.google.com/websites?q=Facebook.com $\% 2 \mathrm{C}+$ Wikipedia.org\&geo =all\&date $=$ all\&sort $=0 \quad($ These stats only count people accessing Facebook via Google search result links; many people now also access Facebook directly, e.g., via apps on their mobile phones, and also access embedded YouTube videos in Facebook.)
} 
Table 1. Facebook presence by type and total 'Likes' received across all journals by each presence type among our sample of general medicine journals ( $n=25$, of 25, 20 had a Facebook presence of any type; a single journal can have more than one type of presence).

\begin{tabular}{lcc}
\hline Facebook Presence Type & $\begin{array}{l}\text { Number of Journals (with this } \\
\text { type of presence) }\end{array}$ & $\begin{array}{l}\text { Likes (total across all journals } \\
\text { per type of presence) }\end{array}$ \\
\hline Full Facebook Page & 9 & 321,267 \\
Facebook Group & 1 & 251 \\
Page Pulled from Wikipedia & 12 & 707 \\
Other (Parent Publisher/Association Presence) & 5 & 81,589 \\
\hline
\end{tabular}

AM J PREV MED, CLEV CLIN J MED, PREV MED, BRIT MED BULL, AM J MANAG CARE, TRANSL RES, MED CLIN N AM, J GEN INTERN MED). Information gathered for each title included JCR rank; homepage URL; imprint; type and size of official Facebook presence if any; type and size of official Twitter presence if any; the presence of Facebook and (or) Twitter connection information on the journal homepage if any; and the presence of Facebook and (or) Twitter sharing options on article-level pages for the journal.

Types of Facebook presence vary from presence via the parent organization or publisher, to a specific journal title presence via Facebook groups, auto-generated Facebook pages pulled from Wikipedia, and (or) a full Facebook presence specifically created for the journal. Size of presence was measured through 'Likes' for Facebook pages, 'Members' for Facebook groups, and 'Followers' for Twitter accounts. For any specific category, data were collected on the same date in order to assure that measures such as 'Likes' would be comparable. All data for this study were collected during the final week of November and the first week of December 2011.

To identify the incorporation of social media presence on the journal homepage or Web site, the homepage was scanned for the icons for either Facebook or Twitter, with a search-in-page for the terms, or searched for the words 'follow us', 'share' or 'connect'. Article-level sharing options typically included bookmarking, citation tools, table of contents alerts, and email alerts. This article reports only on the use or presence of sharing options for Facebook and (or) Twitter.

\section{Results}

All of the surveyed leading general medicine journals had a conventional Web site devoted to the journal and 20 of 25 had some sort of Facebook presence, with 11 of 25 having a Twitter presence. All of the top 15 journals had some kind of Facebook presence, while eight of the top 10 also had a Twitter presence. In the case of BMC Medicine, both Facebook and Twitter accounts belonged to the publisher (BioMed Central), instead of the specific journal title. Seven of the top 10 had a full Facebook page or group devoted explicitly to the specific journal title. Of the top 10 , only two relied on a publisher or association presence instead of one for the individual journal title, and only one had no official Facebook presence, relying solely on the auto-generated Facebook-Wikipedia integration page.

Measuring 'Likes' across all of the full Facebook pages resulted in a total of 321,997 (Table 1), of which 318,267
Fig. 2. Pattern of engagement ('Likes' for whole pages) for general medicine journals with a Facebook presence.

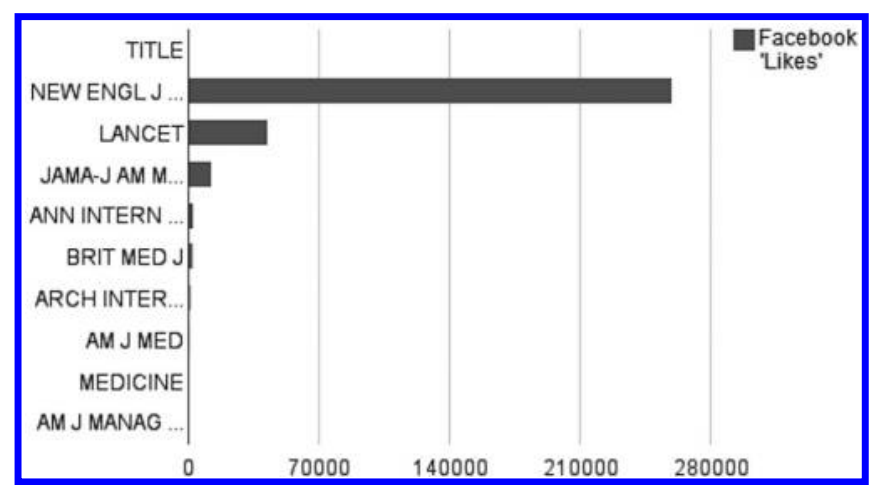

came from the top five titles and 259,902 came from the top title alone (NEJM) (Fig. 2), clearly indicating the influence of the top tier journals. There is insufficient data at this time to show whether the top tier journals are more effective in their use of social media presence, or if their pre-existing influence in print media has carried over into social media.

'Likes' were not significant for any of the other categories of Facebook presence. Note that 'Likes' associated with the Publisher/Association category are not equivalent, as they aggregate across a variety of titles and topics handled by that publisher or association, and cannot be clearly compared as a metric for measuring the influence of a specific journal, although the figures can imply a reflected image of potential influence through association with their parent organization.

Given that Facebook was launched about 3 years prior to Twitter and tended to be adopted for use earlier, with an active user base that is eight times larger than that of Twitter (as of 2011, 800 million versus 100 million [26]), it is perhaps not unexpected that Facebook 'Likes' reflect overall larger numbers than Twitter 'Followers'. While the total numbers of Twitter 'Followers' is smaller across the combined general medicine journals in our sample (Fig. 3), Twitter 'Followers' provide more varied and interesting data. Of particular note is that for journals below the top two slots, Twitter 'Followers' may be equal or greater than Facebook 'Likes' (Fig. 4).

The presence or lack of Facebook and (or) Twitter features (links on homepage and per article sharing options) on each journal's Web site is presented in Table 2. Seven of the surveyed journals did not have any mention of Facebook or Twitter on their Web sites (rows 
Fig. 3. Pattern of engagement ('Followers') for general medicine journals with a Twitter presence.

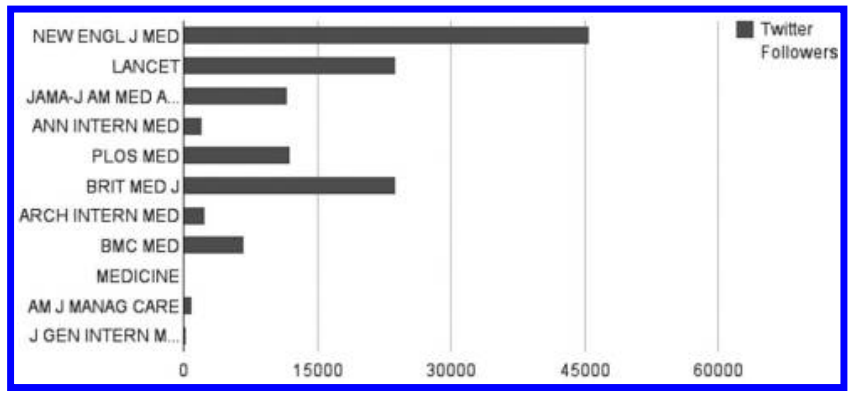

highlighted in grey in Table 2), including those five journals with no Facebook presence of any kind.

\section{Discussion}

Page 'Likes' represent unique Facebook user accounts and potentially a similar number of unique real humans holding the corresponding Facebook accounts. Thus, the top two journals in our sample (NEJM and The Lancet) were able to reach out to hundreds of thousands of Fans via Facebook alone (it should be noted that a single reader might 'Like' more than one Facebook presence type of the same journal and (or) more than one journal in our sample). However, Facebook being a social network, the effects of 'Friends of Fans', and 'Reach' (to people who are not immediate Fans) cannot be ignored; hundreds of thousands of page 'Likes' could translate into millions of potential readers, thanks to the sharing and 'viral' natures of social media.

In other words, 'Likes' on Facebook and 'Followers' on Twitter should not be treated as the equivalents of total accesses. Some people might still visit and read material on a Facebook page without 'Liking' it first, if the page is designed in such a way to be open and not require 'Liking' it to see its content. Should journals make their Facebook 'closed', requiring a 'Like' first in order to access content? This might increase the number of 'Likes' (or might not), but might also put off some users (not wanting to be "forced" to 'Like' a page this way) from reading about what the journal has to offer. Some persons might track content closely without clicking 'Like' because for whatever reason they do not want their name to be publicly associated with the journal (pages that a user 'Likes' will appear on his/her Facebook profile 'Info' tab), or because they already track the journal through some other venue such as e-mail TOC (Table of Contents) subscription or RSS feed.

Twitter Replies and @,Mentions ${ }^{4}$ might also be a measure of popularity or impact and user interaction with a journal's posts on Twitter. Other measures of how much the journal's messages and posts are getting 'amplified' [21, 27] in the 'Twittersphere' and of impact and influence through Twitter include being added to 'Lists'
Fig. 4. Comparing patterns of engagement for general medicine journals with both Facebook and Twitter presences.

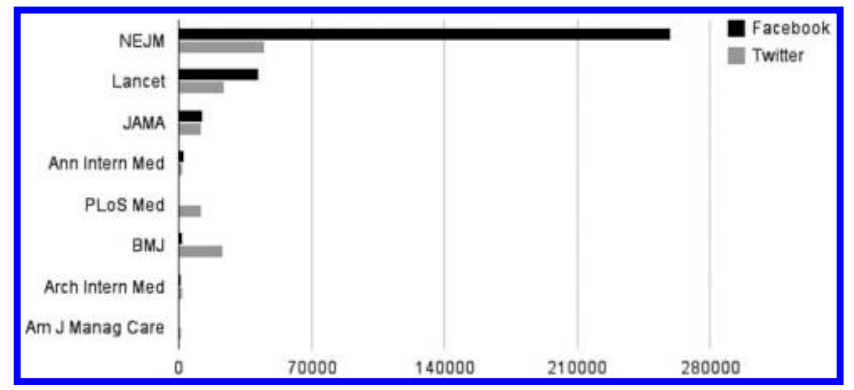

curated by other Twitter accounts (and the number of those 'Lists'), 'Retweets' by other Twitter accounts, independent mentions of the journal or links to its articles, the journal name or acronym being used as a hashtag ${ }^{5}$ such as '\#JAMA', and the content shared in the journal's Twitter stream. Best practices for social media listening and engagement are beyond the scope of the current article, but it deserves to mention here that tools do exists to assist with real-time capture and monitoring of the 'Twittersphere' buzz around a brand and its account(s), content, and hashtags. ${ }^{6}$

Those journals in our surveyed sample making best use of the open-sharing nature of social media (NEJM, The Lancet, and JAMA) are closed-access journals, with payment required to read the full-text of many of their articles. The leading open access (OA) journals on the list, PLoS MED and BMC MED, (BMC MED does not have a dedicated journal presence on Facebook, but rather a Publisher presence for the whole portfolio of BioMed Central's core, in-house titles), are comparatively lagging in terms of their use of social media, the richness of their journal-specific social media experience and the popularity ('Likes' and 'Followers') of their social media presences. This might seem ironic given the open-sharing mandate of OA journals, but could be partially interpreted by considering the general popularity among medical professionals and age and (or) impact factor of the top performers; also NEJM was among the very earliest journals to use social media (around 2005/2006), so it had time to build a strong presence over the more recent adopters of social media.

\section{Four months on: a sustained growth for the top two journals in the surveyed sample}

A little more than 4 months after our original data collection, we decided to update our figures for NEJM and The Lancet, being the two most popular journals among all 25 journals we have surveyed regarding the numbers of their Facebook and Twitter Fans and Followers. We found that NEJM's Twitter Followers increased from 45,520 (when checked during last week of November 2011) to 60,527 (on 3 April 2012), while The Lancet's Twitter Followers grew at a slightly slower rate during the same

\footnotetext{
${ }^{4}$ Twitter help center: What are @ Replies and Mentions?: http://support.twitter.com/articles/14023-what-are-replies-and-mentions

${ }^{5}$ Twitter help center: What Are Hashtags ("\#" Symbols)?: http://support.twitter.com/articles/49309-what-are-hashtags-symbols

${ }^{6}$ To get an idea about how this works, see the 'Twitter buzz box' example at http://ushahidi.com/
} 
Table 2. Presence of Facebook and/or Twitter features on each journal's Web site at homepage level, as well as the presence of per article Facebook and/or Twitter sharing options ( $\mathrm{Y}=$ Yes; $\mathrm{N}=\mathrm{No}$ ). Rows highlighted in grey are journals with no mention of Facebook or Twitter on their Web sites.

\begin{tabular}{llll}
\hline Journal Title & $\begin{array}{l}\text { Connect on/'Like' us on } \\
\text { Facebook }\end{array}$ & $\begin{array}{l}\text { Connect on/Follow us } \\
\text { on Twitter }\end{array}$ & $\begin{array}{l}\text { Per Article Facebook and/or } \\
\text { Twitter Sharing }\end{array}$ \\
\hline NEW ENGL J MED & Y & Y & N \\
LANCET & Y & Y & Y \\
JAMA-J AM MED ASSOC & Y & Y & Y \\
ANN INTERN MED & $\mathrm{Y}$ & $\mathrm{Y}$ & $\mathrm{Y}$ \\
PLOS MED & $\mathrm{Y}$ & $\mathrm{Y}$ & $\mathrm{Y}$ \\
BRIT MED J & $\mathrm{Y}$ & $\mathrm{Y}$ & $\mathrm{Y}$ \\
ANNU REV MED & $\mathrm{Y}$ & $\mathrm{Y}$ & $\mathrm{Y}$ \\
ARCH INTERN MED & $\mathrm{N}$ & $\mathrm{N}$ & $\mathrm{N}$ \\
CAN MED ASSOC J & $\mathrm{N}$ & $\mathrm{N}$ & $\mathrm{N}$ \\
COCHRANE DB SYST REV & $\mathrm{N}$ & $\mathrm{N}$ \\
J INTERN MED & $\mathrm{N}$ & $\mathrm{N}$ & $\mathrm{Y}$ \\
BMC MED & $\mathrm{N}$ & $\mathrm{Y}$ & $\mathrm{N}$ \\
MAYO CLIN PROC & $\mathrm{N}$ & $\mathrm{Y}$ \\
AM J MED & $\mathrm{N}$ & $\mathrm{N}$ & $\mathrm{N}$ \\
ANN FAM MED & $\mathrm{N}$ & $\mathrm{N}$ \\
ANN MED & $\mathrm{N}$ & $\mathrm{N}$ & $\mathrm{Y}$ \\
MEDICINE & $\mathrm{N}$ & $\mathrm{Y}$ & $\mathrm{Y}$ \\
AM J PREV MED & $\mathrm{Y}$ & $\mathrm{Y}$ & $\mathrm{N}$ \\
CLEV CLIN J MED & $\mathrm{Y}$ & $\mathrm{N}$ & $\mathrm{Y}$ \\
PREV MED & $\mathrm{N}$ & $\mathrm{N}$ & $\mathrm{N}$ \\
BRIT MED BULL & $\mathrm{N}$ & $\mathrm{N}$ & $\mathrm{Y}$ \\
AM J MANAG CARE & $\mathrm{N}$ & $\mathrm{N}$ & $\mathrm{N}$ \\
TRANSL RES & $\mathrm{N}$ & $\mathrm{N}$ & 15 \\
MED CLIN N AM & $\mathrm{N}$ & $\mathrm{N}$ & \\
J GEN INTERN MED & $\mathrm{N}$ & 10 & \\
TOTALS (Y) & $\mathrm{N}$ & & \\
\hline
\end{tabular}

period from 23,873 to 33,046. On 3 April 2012, NEJM was following 51 Twitter accounts, ${ }^{7}$ while The Lancet was only following 40 accounts. ${ }^{8}$ While the number of people an organization is following on Twitter could potentially increase that organization's Followers and indicate its engagement with its audience, this seems not to be the case with NEJM and The Lancet, as evidenced by the very small numbers of Twitter accounts they are following.

NEJM Facebook Fans (page 'Likes') also increased during the same period from 259,902 (when checked on 25 November 2011) to 293,505 (on 3 April 2012). The corresponding figures for The Lancet were 42,369 and 45,584. Facebook posts by both journals range from journal paper links and links to news articles about papers they have recently published, to clinical photo quizzes ${ }^{9}$ and embedded podcasts. ${ }^{10}$ Moreover, when logged into Facebook, one can also often see on the journals' Facebook pages posts by other Facebook users in which the journals were mentioned ('Stories by Others'). Some Facebook posts by both journals have attracted considerable numbers of individual post 'Likes' (not to be confused with the main page 'Likes') and comments. ${ }^{11}$ We also noted that NEJM is using HootSuite to post to Facebook. ${ }^{12}$ HootSuite is a commercial dashboard that allows users to manage their social networks (including support for multiple social profiles), schedule messages and tweets, track brand mentions, and analyse social media traffic, among other functions.

NEJM in particular is making very good use of the new Facebook 'Timeline for pages' feature introduced by Facebook at the end of February 2012 [28]. They are using it to tell the history of the journal since it was founded in 1812 .

Social networks can offer journals a better way of reaching their readers than through their own Web site. Marketing and communication departments at various organizations have long realized that large numbers of the people they want to reach and influence are already on Facebook [29]. However, it should be noted that, the creation of Facebook pages being free (Facebook does not

\footnotetext{
${ }^{7}$ See https://twitter.com/\#!/NEJM/following

${ }^{8}$ See http://twitter.com/\#!/TheLancet/following

${ }^{9}$ For example: http://tinyurl.com/NEJM-FB-Photo-Quiz

${ }^{10}$ For example: https://www.facebook.com/TheLancetMedicalJournal/posts/306802782690855

${ }^{11}$ For example, the following NEJM post written as a multiple choice clinical question received 164 'Likes' and 64 comments as of 3 April 2011: https://www.facebook.com/TheNewEnglandJournalofMedicine/posts/10150664064623462

${ }^{12}$ HootSuite: http://hootsuite.com/
} 
Fig. 5. Screenshot of N Engl J Med Facebook page as at 4 April 2012 showing the journal's very good use of Facebook 'Timeline for pages' feature to chronicle the history of the journal.

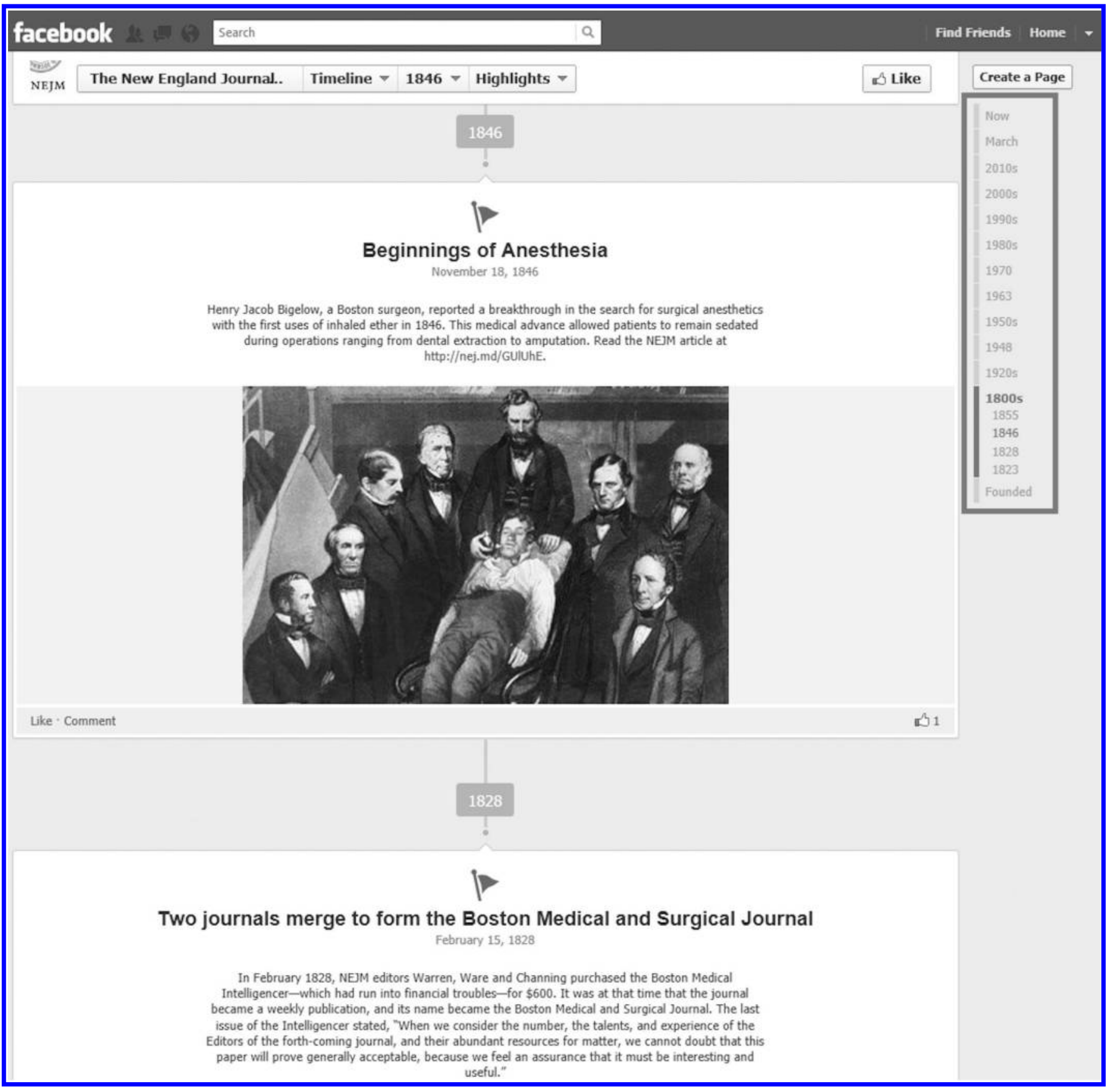

collect any charges for creating a page), journals do not "own" their Facebook page in the same way they own their main Web portal/server/domain name, and disputes over ownership and control might arise [29]. Short provides an excellent opinion piece about 'who really owns pages on Facebook' [30].

\section{Some practical recommendations to journals wanting to establish or improve their social media presence}

The following recommendations are based on the authors' personal experiences, readings on best practices, and observations in Facebook and Twitter over the past years. Both authors have their own popular Facebook and Twitter accounts, and the first author runs the Facebook page and Twitter account for a peer-reviewed journal that he is editing (not among the sample surveyed in this study).

- Have rich and regularly updated content: For those journals that are new entrants to social media, Twitter may prove as valuable if not more so than Facebook, while using both seems to maximize the benefit of each. For a journal's social media presence on Facebook, the most impact seems to come from a devoted Facebook page specific to the journal title. Having rich content on 
Fig. 6. Available to page owner(s) via page 'Admin Panel', Facebook Insights offers a comprehensive range of statistics about a page (Page statistics), its users (Audience demographics) and its individual posts (per-post statistics). Extensive inline help ('balloon help') is offered for every element and chart. The data can be exported in Excel or CSV format for further analysis outside Facebook (Export options). Note how only 74 Fans (whole page 'Likes') in the Insights example shown in this screenshot had a total of 20,454 Friends ('Friends of Fans'), thus amplifying the total page 'Reach' and exposure beyond the immediate group of page Fans.

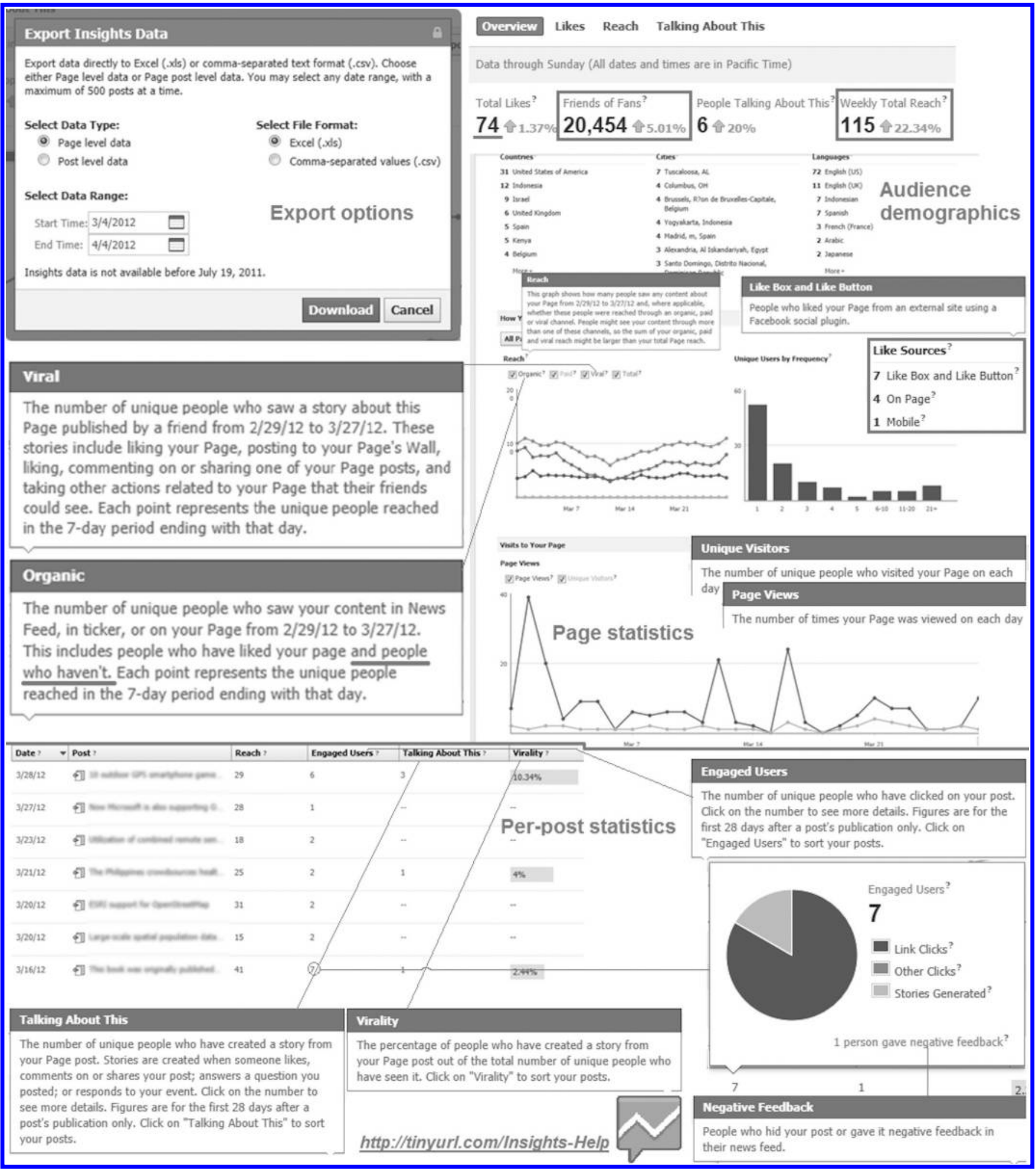


that page rather than mere sporadic 'Wall' posts and a static 'Info' section is crucial to maintaining a strong social media presence and fostering a thriving community around it. (For example, the NEJM Facebook page offers a 'What's New@ NEJM' section featuring the latest articles from NEJM, an 'Image Challenge' quiz rubric, and Twitter integration (tweets available from within their Facebook page).) Consider linking the journal's Twitter account to its Facebook page. Aggregator tools such RSS Graffiti ${ }^{13}$ can also help by initially populating a Facebook presence with automatic and regular RSS feed updates from different sources (e.g., an existing "latest articles/TOC' RSS feed from journal's Web site) on the journal's Facebook 'Wall'.

- Add 'per article' social media sharing and 'Liking' options/buttons on the main journal Web site (see examples of journals already doing so in Table 2): This has the potential of increasing individual article exposure [21] and overall journal discoverability and citations via social media.

- Advertise well: Advertising a journal's social page is equally crucial. This can be achieved through the proper use Facebook $\mathrm{Ads}^{14}$ and contests with prizes, where entry is restricted to those who "Like" the journal's Facebook page. Facebook Ads involve spending some money but offer a very well-targeted form of advertising to bring new Facebook users to a journal's Facebook page. Ads can tell a user, 'Your friends on Facebook (Facebook will display some actual friend names) like this journal page - click to visit and like it'. Twitter also has its own advertising options that might be worth exploring. ${ }^{15}$ Other forms of page promotion include email campaigns featuring the Facebook page link and asking recipients to 'Like' the page in order to have all updates seamlessly integrated into their Facebook News Feed. Webmasters can also add a 'Facebook Like Box' (Facebook Social Plugins [31]) and 'Twitter Updates' box on the journal's main Web site or include prominent links on the homepage to the journal's social media presences.

- Launch dedicated journal apps for Facebook and mobile devices: 'You build it and people will come' is no longer a working principle of today's Web; the new motto is 'You need to go where people already are [30]. Traditional newspapers such as the Washington Post and The Guardian have built their own Facebook and mobile social apps to reach out to their readers [32]. NEJM is already offering an app for the iPad that allows users to share articles via Facebook and Twitter. ${ }^{17}$ The updated
Facebook Open Graph protocol ${ }^{18}$ offers many new options and possibilities for building more powerful Facebook apps.

- Fight spam: Facebook and other social media also open the possibility for 'journal clubs' and post-publication open review and commenting by readers [8]. But with users being able to freely write text and post comments on a journal's Facebook 'Wall', maintainers of Facebook pages should regularly monitor their Facebook 'Wall' for any forms of spam or abuse. Account administrators should also protect their presences with strong passwords to thwart hackers [33].

- Monitor Facebook page and Twitter account popularity and impact statistics: In addition to the total number of page 'Likes' and number of '(people) talking about this' (as well as individual post 'Likes' and 'Shares'), all of which are usually visible to any page visitor, the Facebook page admin(s) can get much more detailed 'Insights' ${ }^{\text {'19 }}$ about how the journal's page and individual posts on it are being received or are growing in popularity ('Virality') on the Facebook network, including 'Page Views' and 'Tabs (sub-sections) Views' (the latter two statistics are a better measure of total accesses than 'Likes'). Facebook 'Insights Data' also provides administrators with detailed statistics and graphical charts about their audience demographics and growth or shrinkage over time. For measuring a journal's Twitter influence and reach, besides the public statistics displayed on a Twitter account page such as number of 'Followers' and 'Lists', there are a number of Twitter analytics tools that might be worth trying, including Klout ${ }^{20}$ and some others $[34,35] .{ }^{21}$ Klout can also be used to measure the influence of a Facebook presence. However, there have been objections to using it (alone) as a reliable metric; Klout results should always be interpreted 'with a grain of salt' and in conjunction with other tools and metrics, e.g., Facebook comments as a metric for readers' engagement $[34,35]$.

\section{Data limitations of the present study}

In the current preliminary study, resource and other constraints meant that the data we collected and analyzed were rather limited. Much of the interesting and rich data are only readily available to social media page administrators and conducting a detailed analysis of a journal's social media traffic would require special arrangements to access samples of these data. Facebook, for example,

\footnotetext{
${ }^{13}$ RSS Graffiti: http://www.rssgraffiti.com/

${ }^{14}$ Facebook Ads: https://www.facebook.com/advertising/

${ }^{15}$ Twitter Promoted Accounts and Advertiser Analytics http://business.twitter.com/advertise/promoted-accounts/ and http://business. twitter.com/advertise/analytics/

${ }^{16}$ Facebook Like Box: http://developers.facebook.com/docs/reference/plugins/like-box/

${ }^{17}$ NEJM iPad Edition: http://itunes.apple.com/us/app/nejm-ipad-edition/id493976598? $\mathrm{mt}=8$

${ }^{18}$ Facebook Open Graph (Beta): https://developers.facebook.com/docs/beta/ and https://developers.facebook.com/docs/beta/opengraph/

${ }^{19}$ Facebook Page Insights-Product Guide for Facebook Page owners: http://ads.ak.facebook.com/ads/FacebookAds/Page_Insights_en_ US.pdf

${ }^{20}$ Klout-The Standard for Influence: http://klout.com/

${ }^{21}$ See also http://www.dailybloggr.com/2009/06/9-tools-to-measure-your-twitter-influence-reach/ and http://twittertoolsbook.com/10awesome-twitter-analytics-visualization-tools/
} 
allows exporting its 'Insights Data' in Excel or CSV (comma-separated values) format, but this functionality is only available to page administrators/owners. The data cover aspects that would be very hard to comprehensively collect manually, such as user engagement with individual posts (per-post statistics: post 'Likes', unique people who have seen the post (or post 'Reach' in Facebook Insights terminology), clickthroughs (or 'Engaged Users' in Insights terminology, including number of persons who gave 'Negative Feedback'/hid the post in their news feed), post shares ('Talking About This' in Insights terminology) and 'Virality'), as well as other aspects that are impossible to collect from the public view of a Facebook page, such as Fans demographics breakdown (by gender, age groups, countries/cities and languages), page 'Like' sources (external 'Like Box', on page or mobile) and the number of page 'Unlikes' during a given period of time. For example, a page might receive 10 new 'Likes' and five 'Unlikes' during a given period of time; the public total 'Likes' figure will only increase by five at the end of that period, which does not tell the complete story about those Fans who chose to leave ('Unlike' the page).

The public nature of most posts on journals' Facebook pages means that anyone who is logged into Facebook can potentially access and read them. Also such posts can be shared on personal and group 'Walls' and on other Facebook pages by anyone logged into Facebook (and not just those who have 'Liked' the corresponding page), which can significantly increase individual post and whole page exposure and reach many more people on Facebook outside a journal's core community of Facebook Fans. Facebook 'Insights Data' again provide some very useful statistics in this respect, namely total page 'Reach' ('Organic', 'Paid', 'Viral' and 'Total'), 'Page Views', 'Unique Visitors', and 'Friends of Fans' counts. ${ }^{22}$ Twitter offers similar stats covering both paid and unpaid activity and traffic (albeit not free; only available for 'Promoted Accounts'), but again these data require liaising with account owners to access them.

\section{Future work}

This preliminary survey should be extended in the near future to cover more biomedical and health science journals, to do a more detailed content analysis of their Facebook and Twitter presences, and to follow the growth of their presences over time (e.g., for 1 year, every 3 months). A broader range of social media spaces, such as YouTube and the Google + social networking site, should also be covered in a future survey, as well as identifying measures for how activity is shown and how it can be tracked in different spaces. It would be desirable to capture best practices or innovative uses from the social media presences of the most successful health and life science journals, perhaps as individual case studies of leading journals focused on their best practices in using the Social Web. The findings for general medicine journals should be compared to those for general science or other topic domains. To facilitate future research of this sort, it would be helpful for journals to provide reciprocal links connecting their social media presences and their homepage, especially for those journals with names that might be confused with other journals or with words in common use, such as Medicine, Science, and Nature.

\section{Conclusions}

Journals should not underestimate the potential of social media as a means of reaching out to, and engaging with their readership [36]. This potential needs to be explored and harnessed by journal editors and publishers, given the increasingly high penetration of Facebook and other social media among Internet users. After all, medical publishing is all about 'dissemination and communication' of research. Social media's sharing and community interaction features facilitate this dissemination, and may be especially critical for the rapid transfer of emerging clinical discoveries for adoption by primary care clinicians to support the bench-to-bedside process.

NEJM and The Lancet could serve as 'success stories' or 'exemplary models' to follow. Their exceptional levels of social media success might be repeatable or might not be; why, why not, and under which conditions, etc. are all questions that future research should attempt to answer.

\section{References}

N.B.: All URLs in footnotes were last checked on 4 April 2012.

1. Dines JS, Bedi A, Dodson CC. Editor's Note-We're on Facebook! J Shoulder Elbow Surg. 2011;20(8):1193. doi:10.1016/ j.jse.2011.10.001.

2. Turakhia MP. JICE goes "social". J Interv Card Electrophysiol. 2011;32(2):79-80. doi:10.1007/s10840-0119621-x.

3. Thoring A. Corporate tweeting: Analysing the use of twitter as a marketing tool by UK trade publishers. Pub Res Quarterly. 2010;26(2):79-95. doi:10.1007/s12109-010-9158-3.

-4. Chopra V, McMahon LF. HITECH, electronic health records, and Facebook: A health information trifecta. Am J Med. 2011;124(6):477-9. doi:10.1016/j.amjmed.2011.01.010.

5. Dolan TC. Social media, ACHE, and me. New media platform can benefit healthcare organizations in many ways. Healthc Exec. 2010;25(3):6.

6. Bottles K. Twitter, an essential tool for every physician leader. Physician Exec. 2011 May-Jun;37(3):80-2.

7. Galloro V. Status update. Hospitals are finding ways to use the social media revolution to raise money, engage patients and connect with their communities. Mod Healthc. 2011;41(11):6-7,16,1.

8. Mandavilli A. Peer review: Trial by Twitter. Nature. 2011;469(7330):286-7. doi:10.1038/469286a.

9. Facebook: Statistics. Retrieved online April 4, 2012 from http://newsroom.fb.com/content/default.aspx?NewsAreaId=22

\footnotetext{
${ }^{22} \mathrm{~A}$ video tutorial exploring some aspects of Facebook 'Insights Data' is available at http://www.youtube.com/watch?v $=6$ aehIYSgYwU
} 
10. The Rise of Social Networking in Latin America. September 2011. ComScore. Retrieved online December 12, 2011 from http://www.comscore.com/Press_Events/Presentations_ Whitepapers/2011/The_Rise_of_Social_Networking_in_Latin_ America

11. Compete: Site Analytics: Facebook.com. Retrieved online December 11, 2011. http://siteanalytics.compete.com/face book.com/

12. Tsotsis A. Twitter Is At 250 Million Tweets Per Day, iOS 5 Integration Made Signups Increase 3x. TechCrunch October 17, 2011. Retrieved online December 12, 2011 from http:// techcrunch.com/2011/10/17/twitter-is-at-250-million-tweetsper-day/

13. Response of Eric Schmidt, Executive Chairman, Google Inc. Before the Senate Committee on the Judiciary Subcommittee on Antitrust, Competition Policy, and Consumer Rights; Hearing on "The Power of Google: Serving Consumers or Threatening Competition?" September 21, 2011. Retrieved online December 12, 2011 from https://docs.google.com/viewer? $\mathrm{a}=\mathrm{v} \&$ pid $=$ explorer $\&$ chrome $=$ true \&srcid $=0 \mathrm{~B} 5 \mathrm{JQZZEEQaEON}$ DJkZWI1MzUtMzk5Mi00ZDRhLWIyZmMtMWRkOWU1 MmU5ZmZk\&hl=en_US

14. Bouchard G. Intentional Targeting: Search vs. Facebook. SearchEngine Watch February 10, 2011. Retrieved online December 12, 2011 from http://searchenginewatch.com/article/ 2067971/Intentional-Targeting-Search-vs.-Facebook

15. Helft M, Hempel J. Facebook vs. Google: The battle for the future of the Web. Fortune Magazine/CNN Money November 29, 2011: 2:11 pm ET. Retrieved online December 21, 2011 from http://money.cnn.com/2011/11/03/technology/facebook_ google_fight.fortune/index.htm

16. Herbert G. Americans now spend more time on Facebook than Google, Yahoo, Twitter, Tumblr and YouTube combined. Syracuse.com September 12, 2011. Retrieved online December 12, 2011 from http://www.syracuse.com/news/ index.ssf/2011/09/nielsen_social_media_report_facebook_tumblr_ twitter_google.html

17. Nielsen Social Media Report Q3 2011. Retrieved online December 12, 2011 from http://blog.nielsen.com/nielsenwire/ social/

18. Madden M, Zickuhr K. 65\% of online adults use social networking sites. Washington, D.C.: Pew Research Center, 2011 Aug 26. Retrieved December 13, 2011 from http:// www.pewinternet.org/ /media//Files/Reports/2011/PIP-SNSUpdate-2011.pdf

19. Toth S. Social media revolution: New courses tap into Facebook's growing senior demographic. Retrieved online December 13, 2011 from http://www.baltimoresun.com/ explore/howard/publications/howard-magazine/bs-exho-socialmedia-revolution-20111212,0,6100789.story

20. Dolan PL. Nearly all U.S. doctors are now on social media. Retrieved online December 13, 2011 from http://www.amaassn.org/amednews/2011/09/26/bil20926.htm

21. Eysenbach G. Can tweets predict citations? metrics of social impact based on Twitter and correlation with traditional metrics of scientific impact. J Med Internet Res. 2011; 13(4):e123. doi:10.2196/jmir.2012.
22. Marton C. American Cancer Hospital web sites and adoption of web 2.0 technologies. J of Hosp Librship. 2011;11(3):294304. doi:10.1080/15323269.2011.587104.

23. Chen KN, Sun HC, Lin WC, Lin PC. Into the future: Three keys to success for medical libraries. J Hosp Librship. 2011; 11(4):348-57. doi:10.1080/15323269.2011.611105.

24. Farrell A, Mayer SH, Rethlefsen ML. Teaching web 2.0 beyond the library: adventures in social media, the class. Med Ref Serv Q. 2011;30(3):233-44. doi:10.1080/02763869.2011.590413.

25. Lemley T, Burnham JF. Web 2.0 tools in medical and nursing school curricula. J Med Libr Assoc. 2009;97(1):50-2. doi:10. 3163/1536-5050.97.1.010.

26. Gannes L. Twitter finally discloses how many active users it has: 100M (8 September 2011). Retrieved online December 14, 2011 from http://allthingsd.com/20110908/twitter-finallydiscloses-how-many-active-users-it-has- $100 \mathrm{~m} /$

27. Wheeler S. The ripple effect (11 October 2011). Retrieved online December 14, 2011 from http://steve-wheeler.blogspot. com/2011/10/ripple-effect.html

28. Whitney L. Facebook launches Timeline for Pages (CNET, 29 February 2012). Retrieved online April 4, 2012 from http:// news.cnet.com/8301-1023_3-57387495-93/facebook-launchestimeline-for-pages/

29. Drugmaker Merck challenges Facebook after 'losing' page (BBC News, 25 November 2011). Retrieved online December 13, 2011 from http://www.bbc.co.uk/news/technology-1588 8843

30. Short A. Why Facebook's new Open Graph makes us all part of the web underclass (27 September 2011). Retrieved online December 13, 2011 from http://www.guardian.co.uk/tech nology/2011/sep/27/facebook-open-graph-web-underclass

31. Grinberg M. 10 Ways to Add Facebook Functionality to Your Website (December 21, 2011). Retrieved online January 12, 2012 from http://www.socialmediaexaminer.com/10-waysto-add-facebook-functionality-to-your-website/

32. Halliday J. Guardian launches Facebook app (The Guardian, 22 September 2011). Retrieved online December 13, 2011 from http://www.guardian.co.uk/media/2011/sep/22/the-guardianlaunches-facebook-app

33. Cluley G. NHS Direct Twitter account compromised by Acai Berry diet spammers (17 October 2011). Retrieved online December 13, 2011 from http://nakedsecurity.sophos. com/2011/10/17/nhs-direct-twitter-account-compromised-byacai-berry-diet-spammers/

34. Lipowicz A. How to measure social media reach: Counting followers and fans is just the first step (13 December 2011). Retrieved online December 14, 2011 from http://fcw. com/articles/2011/12/13/tips-for-federal-agencies-to-measuretheir-social-media-reach.aspx?admgarea $=$ TC_CLOUD

35. Ben-Yehuda G. Social Media Metrics-Measuring and More: How to find and act on the correct metrics (December 2011). Retrieved online December 14, 2011 from http://www.slide share.net/gbyehuda/social-media-metrics-ft-daft-punk

36. Van Eperen L, Marincola FM. How scientists use social media to communicate their research. J Transl Med. 2011;9:199. doi:10.1186/1479-5876-9-199. 